\title{
The effects of noise pollution on the citizens in Ho Chi Minh City
}

\author{
Danh Nguyen Tan \\ IT Department, FPT University, Vietnam
}

\begin{abstract}
Social development, along with the process of industrialization and modernization of the country has led to a series of negative effects on the natural environment and human living environment. Among them, noise pollution has seriously affected the health and life of the people. While noise pollution causes a lot of harm, people pay little attention to this issue. People living in areas with too much noise often lose sleep and are prone to stress, fatigue, and disease. Moreover, living in a noisy area for too long can lead to heart failure, which can be fatal. If people who are being treated for a disease live in a noisy and polluted place, the recovery process will be slower, or even not recovered. Not only that, but the noise also makes children easily distracted, making their learning and knowledge reception seriously affected. The following article gives researches on the origin, cause and current status of the noise pollution problem in Ho Chi Minh City as well as methods to overcome this situation. Through the process of synthesizing and analyzing data together with survey results, the article mentions the alarming situation of environmental pollution in Ho Chi Minh city and offers some implementation solutions.
\end{abstract}

\section{Introduction}

Noise pollution is an environmental hazard in residential, commercial, industrial and agricultural areas in countries around the world, especially in developing countries. The phrase "noise pollution" is no longer unfamiliar to the social life, but it has "continuously developed" in many different forms, especially as technical and information technology advances [1]. From a medical perspective, the intensity of sound has a serious effect on human health. There are many types of noise that cannot be avoided, but at acceptable levels that do not affect health, but there are cases where the level of noise pollution has reached alarming levels to health [2].

Currently, there are quite a few warnings about dust and noise areas beyond the permitted level. In hot weather, dust and noise have increased environmental pollution causing discomfort for pedestrians. Some areas have synthetic dust within the permissible standards but the noise is in excess of the prescribed standards. One of the main reasons is due to the excessive volume of vehicles, along with the dust discharged from production units. With 13 million people living, concentrated in many industrial zones, Ho Chi Minh City is facing problems with air pollution and noise. Monitoring results in 2017 and at present at 12 points in the city show that air pollution due to dust is up to more than $68 \%$ and noise pollution is nearly $100 \%$, both factors are far above Vietnamese standards. . The source of dust and noise pollution in the city comes mainly from three main types, including pollution caused by traffic activities; pollution caused by industrial activities; pollution arising from urban life with the city's construction and services activities. In addition to internal problems, Ho Chi Minh City is located in the middle of the key economic region of the South, so it is affected by industrial activities and urbanization from provinces such as Binh Duong and Dong. Nai, Ba Ria - Vung Tau, Long An province. This article mainly addresses the alarming noise pollution situation that has been occurring.

\section{Research content}

\subsection{Literature review}

Noise pollution is the sounds that cross a specific threshold, causing discomfort to those around them. In some countries around the world, noise pollution can come from vehicles, transport, motor vehicles, trains and planes. Not only that, the noise from factories, factories in the process of industrialization and modernization is also the cause of noise pollution. Noise pollution is considered to be one of the health hazards of everyone. According to the World Health Organization (WHO), in the past 30 years, noise pollution has become complicated, directly affecting the environment and quality of life of people, especially in developing countries, including Vietnam [2].

Sound measured in decibels $(\mathrm{dB})$ up about $76 \mathrm{~dB}$ starts to have an annoying sound threshold. And according to experts, the hearing threshold within the human tolerance limit is about $110 \mathrm{~dB}$. However, the sounds emitted around the residents every day are almost beyond the standard level, for example the noise coming from the expressway during peak hours and the distance of $15 \mathrm{~m}$ from $76 \mathrm{~dB}$; a street car at $105 \mathrm{~km} / \mathrm{h}$, the sound 
$8 \mathrm{~m}$ away is at $77 \mathrm{~dB}$; a diesel truck that covers speeds of $65 \mathrm{~km} / \mathrm{h}$. The sound obtained 15 meters away is $88 \mathrm{~dB}$; the aircraft 300 meters above the ground produces a sound of $88 \mathrm{~dB}$; Lawn mower motor makes a noise of 96 $\mathrm{dB}$; fighters 737 or DC-9 at an altitude of $1,853 \mathrm{~m}$ land with a sound of $97 \mathrm{~dB}$; The noise from rock performances ranges from 108 to $114 \mathrm{~dB}$.

\subsection{Causes of noise pollution}

The cause of noise pollution in human life can come from many aspects, especially natural causes and man-made causes [3].

First, natural noise pollution can be mentioned as earthquake and volcanic activity. Although natural pollution does not happen regularly and continuously, each time it happens, its impact is extremely large. This is also not a source of cyclical noise, it happens randomly, so we need to take precautions. Vietnam is not a country affected or affected by earthquake or volcanic activities [4].

Next, it can be said that the main cause of noise pollution is man-made. The first can be mentioned is due to vehicles such as motorbikes, trains, planes, motor vehicles, etc. Currently, means of transport are increasing with dizziness, the density of vehicles on the street is increasing. It causes noise pollution due to engine noise, sirens as well as vehicle brakes [3]. In Vietnam, the number of poor-quality vehicles circulating on the street has created considerable noise pollution, causing people to suffer heavily when in traffic. Although planes are not too many vehicles, the level of noise pollution it generates is much higher than that of other vehicles [5]. The time when the plane takes off or lands is the time when the households living near the plane are exposed to a relatively small sound frequency. The second reason is the noise generated from industrial buildings. Active industrial buildings produce extremely loud noises that annoy the neighborhoods living nearby [6]. This noise can be caused by the operation of machines, the operation of construction works. This source of noise can be said to be extremely abundant and continuous. In industrial and manufacturing activities, the use of machines is considered indispensable. However, due to the awareness of some businesses or production establishments, some industrial zones do not have appropriate measures, making the level of noise pollution on the rise [2]. Furthermore, the use of construction machinery is quite common. This is a significant source of noise pollution. The last cause is the noise that arises in daily life. Maybe screams, maybe loud music, noise from phones, music players, etc. So if we talk about the degree of influence, this is also a significant source of influence on our hearing.

\subsection{Current situation of noise pollution in Ho Chi Minh City}

Along with the pollution of various types of waste, air, and noise pollution, is also at the red alert level for some big cities in Vietnam. Noise pollution is proportional to the urban development; the more developed the urban area, the higher the pollution level, in which Ho Chi Minh City must be included [1].

The current noise pollution in Ho Chi Minh City is truly alarming. Noise measurement results at 150 monitoring points located on 30 city roads in the least traffic time (from 22:00 to 6:00 the next day) but the measured noise still exceeded the limit much. This will have a direct impact on the daily life and health of the people and need to be handled quickly by functional agencies [3].

In Vietnam, based on the national technical standards for noise, for specific areas (areas from the fences of health care centers, libraries, kindergartens, schools, churches, temples, pagodas and areas that have other specific rules), the allowed sound from 6 to 9 o'clock is $55 \mathrm{~dB}$, from $9 \mathrm{pm}$ to $6 \mathrm{am}$ another $45 \mathrm{~dB}$. For normal areas (apartment buildings, houses in alley, resorts, motels, administrative offices, etc.), from 6:00 to $21: 00$ is $70 \mathrm{~dB}$, from 21:00 to 6:00 Brightness is $55 \mathrm{~dB}$. However, in reality, we have to live with sounds that are beyond our limits on a regular basis [4].

It is said that 1 out of 3 noise sources in urban area is industry, traffic, construction - service, traffic noise pollution is the worst. Measurements of new noise pollution observed on some roads in Ho Chi Minh City have exceeded the permitted level many times. From the survey results, there are quite a few places with high noise pollution, such as the intersections of main roads during rush hour. Even late at night, in other words, from 11:00 to 6:00 am, the measured sound levels were not within the allowable limits [4].

Not only that, the rather loud sound from the portable speakers used to play music or sing karaoke is one of the familiar sounds on the streets of Ho Chi Minh City in recent times. It is worth mentioning, this type of sound is played regularly on populated streets or places to buy and sell, affecting people. According to the technical regulations of the Ministry of Natural Resources and Environment, the noise of $70 \mathrm{dBA}$ or less is within the standard while the noise of some places is up to 83.5 dBA [4].

If other types of pollution are concerned, noise pollution is somewhat overlooked, although it affects human health as well as other types of pollution. According to many studies, people living in areas with too loud noise often lose sleep and are prone to stress, fatigue and disease. More seriously, living in a noisy area for too long can lead to heart failure, which can affect lives.

\subsection{Effects of pollution on city dwellers}

In fact, the noise pollution causes more serious problems than anyone imagined [7]. If exposed in an environment with too much noise, in the long run it will be difficult for people to reach around as quickly as possible and thus solving problems will slow down. For example, we cannot focus on work or study when there is too much noise nearby. Therefore, if hospitals, schools and offices are located on the main roads with frequent noise pollution, these works must have soundproof glass. 
Noise has a direct effect on human hearing and if exposed to noise for a long time, it will be easy to lose hearing, affecting the nervous system and health of each person. Noise pollution also causes memory loss, high blood pressure, and severe mental effects [5].

If residing in an environment with too loud sounds causes not only emotional problems but also damage to the inner ear, the auditory nerve will contract. For children, noise pollution distracts them, affecting the effectiveness of word learning in the first years of life. Each of these impacts contributes to negative mental, physical and behavioral manifestations, affecting labor efficiency, especially for urban residents [8].

Furthermore, noise has a definite effect on animals. Accordingly, it increases the risk of death of animals when the biological balance is changed. Specifically, for predators, it becomes more difficult to forage. Hunting is no longer effective due to increased human-induced noise pollution. Meanwhile, birds will become less loyal to their mates due to exposure to traffic noise. This changes the evolutionary laws of some species and has serious genetic and evolutionary consequences [9]. Besides, noise pollution in the ocean also has a significant impact on species because these species all use sound waves to forage and forage. However, the sound they emit is overwhelmed by noises from ships, ultrasonic waves from military ships. This makes them disoriented, unable to find mates. According to a report by the International Fund for Animal Protection, the distance with which blue whales communicate with each other has been reduced by up to $90 \%$ due to increasing noise pollution over the past 40 years [3].

\subsection{Methodology}

This article is conducted according to online survey methods from which statistics, synthesis and analysis are based on the opinion of a group of students studying Japanese language in the 3rd and 4th years of FPT University in Ho Chi Minh City on September 20, 2020.

\subsection{Results and Discussion}

After analyzing the results in the figure below, we understand that along with the pollution of various types of waste, air, and noise pollution, there is also at a red alert level for some big cities in Vietnam, including Ho Chi Minh City.

Through the results of the study from chart 1 , we can see the severity of the noise pollution problem in Ho Chi Minh City and its level of conservation. $100 \%$ of people doing the survey think that the current noise pollution problem is of some degree, $50 \%$ of them feel the problem is extremely serious. Moreover, through a number of other surveys, $100 \%$ of individuals are affected by their health and life due to the sound exceeding the permitted regulations.

Although noise pollution is harmful to human life and health, but from the chart 2, we can see that a part of people are still not paying attention to this issue, accounting for $25 \%$ of people do the survey. This is extremely dangerous, because if people do not pay attention in time and start taking preventive measures in time, their health and spirits will deteriorate without knowing the reason (Table Item 2).

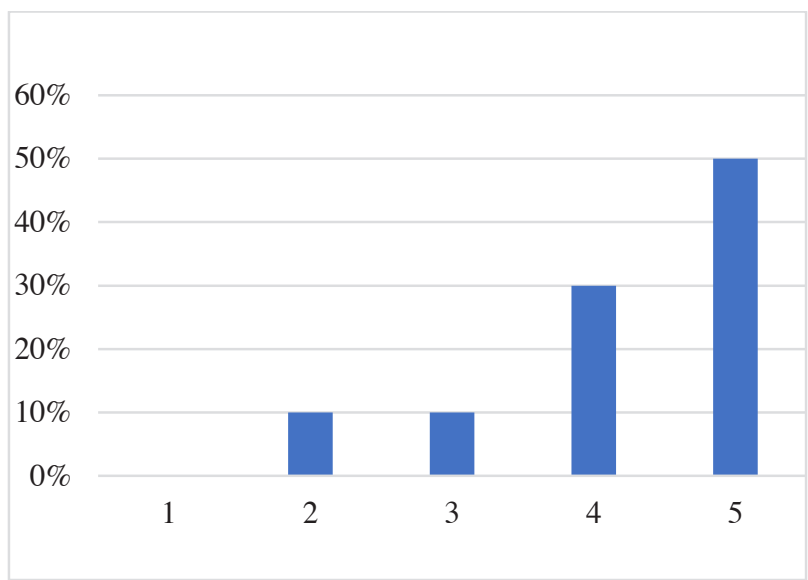

Figure 1: The severity of the noise pollution problem in Ho Chi Minh City

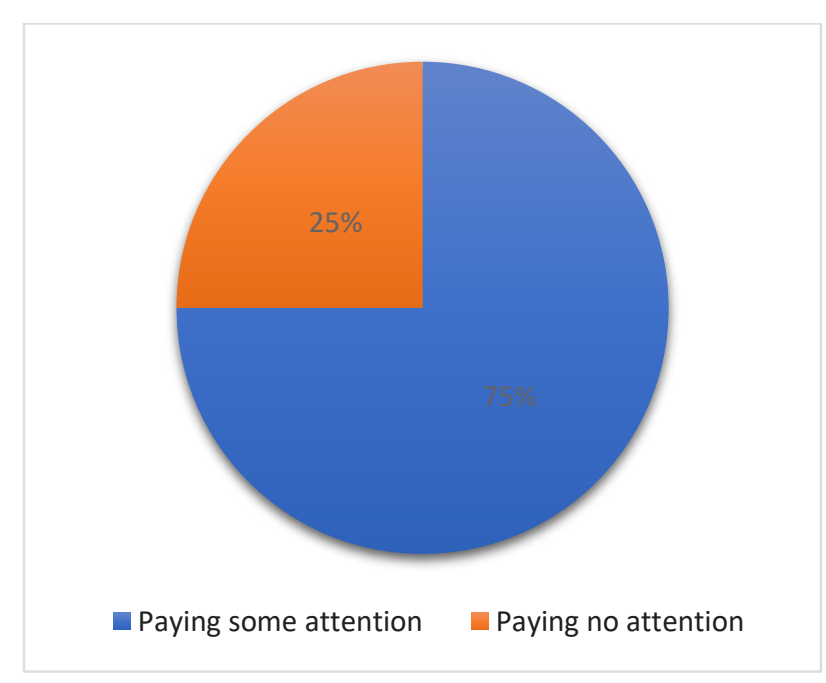

Figure 2: Notable level of noise pollution problem in $\mathrm{Ho}$ Chi Minh city

\subsection{Some proposed solutions}

There are 2 basic solutions to deal with noise. Active noise reduction solution by using noise reduction measures at source by designing and fabricating silencers, applying them to aircraft, truck, passenger car, mechanical engine industrial, home noise equipment. This method focuses on improving machine designs and machine operating procedures; controls vibrations and enhances sound-absorbent absorption with absorbent, absorbent materials

This method is applied quite commonly, but only partially reduces the noise of equipment that generates noise such as engines, equipment, machines, factories, etc.

Passive noise reduction solution is the one using sound-absorbing and sound-proofing materials to control noise in public buildings, where noise comes from many different causes. For example, at a station hall, airport, 
hospital, or school, noise comes from many reasons that need to be handled to ensure the required noise level, minimize the impact of noise to work, to human activities [6]. The handling of noise with soundproof and absorbent materials must ensure the quality, at the same time have the size and design suitable for public works, easy to clean, install and have high durability.

At the recent 20th session of Ho Chi Minh City People's Council, singing karaoke with loud speakers to make noise in the conventions and conventions of the neighborhood and hamlet is not allowed under any circumstances. In fact, the culture of using sound in Vietnam is still very limited, in a strong way that everyone uses it without paying attention to the regulations or the people around. In addition to the people's awareness, public opinion said that the competent authorities still lack determination in handling. The sanctioning of violations of the regulations on ensuring the general quiet is specified in Decree No. $167 / 2013$ / ND-CP Regulations on sanctioning of administrative violations in the field of social security, order and safety; Prevention of social evils; fire prevention and fighting; domestic violence prevention and control and in Decree No. 155/2016 / ND-CP on sanctioning of administrative violations in the field of environmental protection. Accordingly, if causing loud noises, making noises or rioting in residential areas or public places during the period from 10 p.m. to 6 a.m., a warning or a fine of 100,000 to 300,000 VND (5 USD to 15 USD) for individuals; from 200,000 to 600 thousand VND (10 USD to 30 USD) for the violating organization; the facility will be suspended for up to six months if the noise pollution is high [6].

Traffic noise can be minimized by the use of noise barriers, restricting the flow of vehicles on the street, changing the road surface texture, limiting heavy vehicles, using technology to traffic control, using slippery cars to reduce brakes, tire design, especially horn should be used sparingly. An important factor in adopting this strategy is the road noise warning computer model, which can be resolved at a specific time, showing road conditions, weather, as well as traffic information, in order to minimize and reduce costs for the state [4]. The reduction in traffic construction activities is very limited, so it is necessary to find solutions and have a scientific urban planning plan to avoid noise generation. Aircraft noise can be reduced by using a jet engine that makes no noise. The flight route and timing of the runway is also an important solution, with the primary beneficiaries being the residents near the airports.

\section{Conclusion}

If other types of pollution are concerned, noise pollution is somewhat overlooked even though it affects human health as well as other types of pollution. People living in areas with loud noises often lose sleep and are prone to stress, fatigue and disease. More seriously, living in a noisy area for too long can lead to heart failure, which can affect lives. It can be said that the level of health hazard of noise pollution is not inferior to other types of pollution. The scene of people living with noise is unavoidable in the urban life rhythm. However, if each person raises their sense of self-awareness and respect for others by minimizing the noise they make, then ensuring the quality of the living environment, the health and efficiency of their work is not only their own but also The surrounding people have also been greatly enhanced. In addition, state agencies must also have laws regulating the permissible sound frequencies and penalties for violations. With the cooperation between the people and the government, the noise pollution situation not only in Ho Chi Minh City but across the country will be improved in the future.

\section{Conflict of interest}

There is no conflict of interest in the paper.

\section{References}

1. Phan, H. Y. T., Yano, T., Sato, T., \& Nishimura, T. Characteristics of road traffic noise in Hanoi and Ho Chi Minh city, Vietnam. Applied Acoustics, 715 (2010).

2. Mishra, R. K., Parida, M., \& Rangnekar, S. Evaluation and analysis of traffic noise along bus rapid transit system corridor. International Journal of Environmental Science \& Technology, 74 (2010).

3. Nguyen, X. P. The bus transportation issue and people satisfaction with public transport in Ho Chi Minh city. Journal of Mechanical Engineering Research and Developments, 421 (2019).

4. Hanh, V. T. H. Canal-side highway in Ho Chi Minh City (HCMC), Vietnam-Issues of urban cultural conservation and tourism development. GeoJournal, 663 (2006).

5. Hoi, H. T. Impacts of Urbanization on the Environment of Ho Chi Minh City. In IOP Conference Series: Earth and Environmental Science. IOP Publishing, 5051 (2020).

6. Van Than, L. Economic development, urbanization and environmental changes in Ho Chi Minh City, Vietnam: Relations and policies. Urban Population, Development and Environment Dynamics in Developing Countries Conference, (2007).

7. Verma, R. L., Borongan, G., \& Memon, M. Municipal solid waste management in Ho Chi Minh City, Viet Nam, current practices and future recommendation. Procedia Environmental Sciences, 35 (2016).

8. Gholami, A., Nasiri, P., Monazzam, M., Gharagozlou, A., Monavvari, S. M., \& Afrous, A. Evaluation of traffic noise pollution in a central area of Tehran through noise mapping in GIS. Advances in Environmental Biology, 68 (2012).

9. Sánchez-Sánchez, R., Fortes-Garrido, J. C., \& Bolívar, J. P. Characterization and evaluation of noise pollution in a tourist coastal town with an adjacent nature reserve. Applied Acoustics, 95 2015). 